\title{
Location Monitoring System with GPS, Zigbee and Wifi Beacon for Rescuing Disable Persons
}

\author{
Kohei Arai \\ ${ }^{1}$ Graduate School of Science and Engineering \\ Saga University \\ Saga City, Japan
}

\author{
Taka Eguchi \\ ${ }^{1}$ Graduate School of Science and Engineering \\ Saga University \\ Saga City, Japan
}

\begin{abstract}
Location monitoring system for rescue disable persons by switching the location estimation methods with GPS, ZigBee and WiFi beacon is proposed. Rescue system with triage using health condition monitoring together with location and attitude monitoring as well as the other data acquired with mobile devices is evaluated with the proposed location monitoring system. Through simulation study, influence due to location estimation error on rescue time is evaluated together with effect of the proposed location monitoring system. Also, it is found that the effect of triage on rescue time is clarified.
\end{abstract}

Keywords-Rescue system; Location estimation; Attitude estimation; Health monitoring; Mobile applications; Triage; Rescue planning

\section{INTRODUCTION}

Most computer based simulation evacuation models are based on flow model, cellular automata model, and multiagent-based model. Flow based model lacks interaction between evacuees and human behavior in crisis. Cellular automata model is arranged on a rigid grid, and interact with one another by certain rules [1]. A multi agent-based model is composed of individual units, situated in an explicit space, and provided with their own attributes and rules [2]. This model is particularly suitable for modeling human behaviors, as human characteristics can be presented as agent behaviors. Therefore, the multi agent-based model is widely used for evacuation simulation [1]-[4].

Recently, Geographic Information Systems: GIS is also integrated with multi-agent-based model for emergency simulation. GIS can be used to solve complex planning and decision making problems [5]-[7]. In this study, GIS is used to present road network with attributes to indicate the road conditions.

We develop a task allocation model for search and rescue persons with disabilities and simulate the rescue process to capture the phenomena and complexities during evacuations. The task allocation problem is presented by decision of volunteers to choose which victims should be helped in order to give first-aid and transportation with the least delay to the shelter. The decision making is based on several criteria such as health condition of the victims, location of the victims and location of volunteers [8]-[18].

A rescue model for people with disabilities in large scale environment is proposed. The proposed rescue model provides some specific functions to help disabled people effectively when emergency situation occurs. Important components of an evacuation plan are the ability to receive critical information about an emergency, how to respond to an emergency, and where to go to receive assistance. Triage is a key for rescue procedure. Triage can be done with the gathered physical and psychological data which are measured with a sensor network for vital sign monitoring. Through a comparison between with and without consideration of triage, it may be possible to find that the time required for evacuation from disaster areas with consideration triage is less than that without triage [19]-[20].

These studies do not taken into account location estimation accuracy. GPS utilized location accuracy is assumed to be $100 \%$ accurate (no error). There, actually, are location estimation errors. Other methods for location estimation are available, for instance, ZigBee, WiFi beacon utilizing methods. All the methods have errors which depend on the conditions, location of radio wave absorbance, weather condition, multipath condition, etc. Some of these error sources are controllable except weather condition. A prior to location estimation, location of radio wave absorbance, and multi-path condition can be assessed. It would be possible to use the best accuracy of location estimation method can be used alternatively from among GPS, WiFi beacon, and ZigBee. In particular, ZigBee transmitter can be layout arbitrary in accordance with the required location estimation accuracy. Thus the best location estimation accuracy could be achieved.

The next section describes influence due to location estimation error on the rescue time in concern followed by the proposed location estimation method by using GPS, WiFi beacon and ZigBee alternatively. Then experimental results from rescue simulation studies which is based on triage with health condition of victims. Finally, conclusion is describes together with some discussions.

\section{INFLUENCE DUE TO LOCATION ESTIMATION ERROR ON RESCUE TIME}

\section{A. Comparison of Location Estimation Methods Among GIS, WiFi Beacon and ZigBee Based Methods}

The location estimation with GPS is accurate for outdoor situation with the condition without radio wave absorbance as shown in Fig.1. It, on the other hand, is poor accuracy for indoor situation with the condition with radio wave absorbance. Meanwhile, WiFi beacon based location estimation is available for both indoor and outdoor situations. Accuracy is dependent 
on the number of available routers and the existing radio wave absorbance.

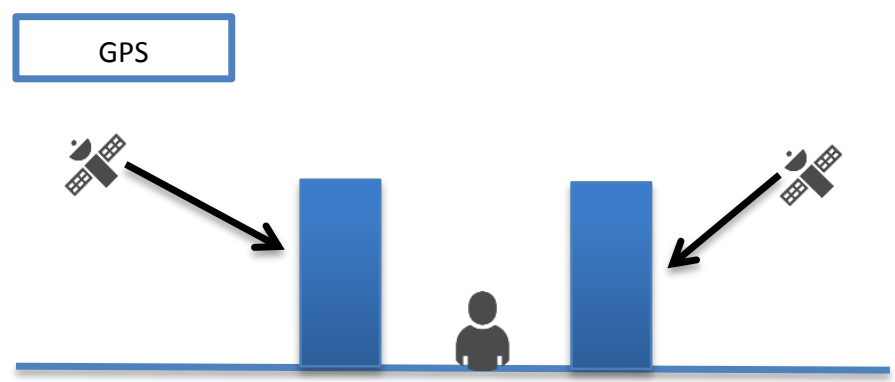

Fig. 1. GPS based location estimation system

On the other hand, ZigBee based location estimation needs very poor power consumption as shown in Fig.2. The size of ZigBee transmitter and receiver as well as repeater is very compact so that it can be set up anywhere. Furthermore, ZigBee transmitter and receiver is relatively cheap in comparison to the $\mathrm{WiFi}$ router. The transmitters of $\mathrm{WiFi}$ beacon router and ZigBee transmitter can be set-up arbitrary depending on the required accuracy.

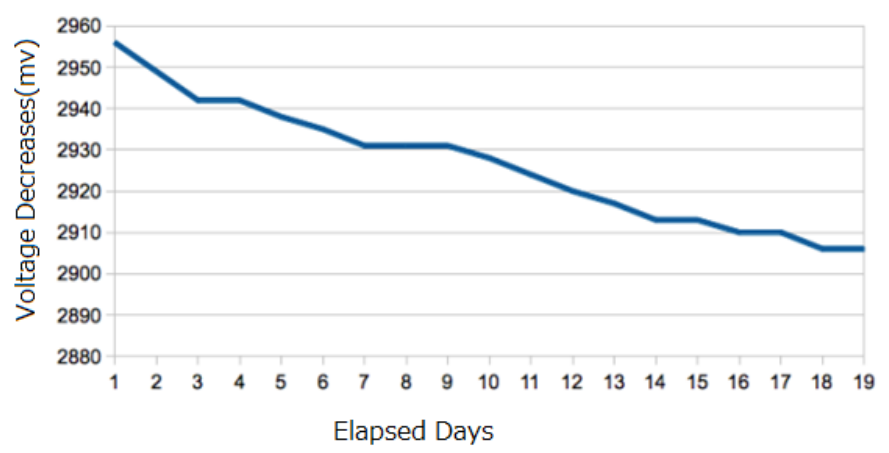

Fig. 2. Power consumption of ZigBee

Measured and theoretical signal strengths of WiFi beacon based location estimation method are shown in Fig.3. The theoretical receiving signal strength is expressed in equation (1).

$$
R S S I=-\left(10 \log _{10} d+A\right)
$$

where RSSI denotes receiving signal strength while $d$ and A denotes distance between transmitter (WiFi router) and receiver as well as signal strength for the case of the distance is $1 \mathrm{~m}$, respectively. Measured signal strength shows a good coincidence to the theoretical strength.

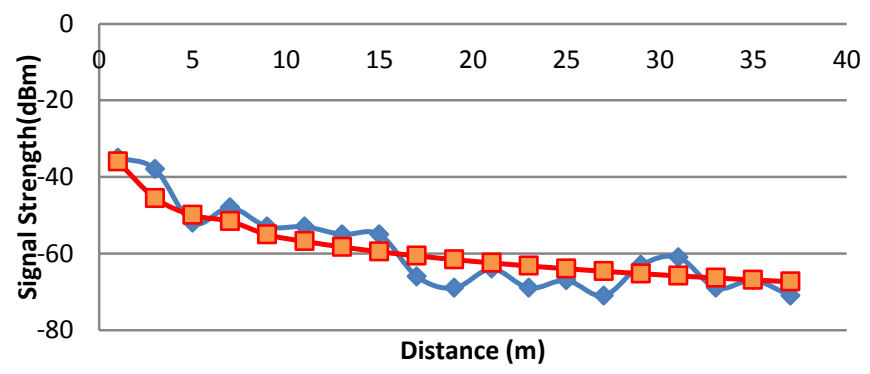

Fig. 3. Measured and theoretical signal strength as a function of distance
On the other hand, measured signal strength of ZigBee receiver as a function of distance between transmitter and receiver is shown in Fig.4 (a) for the indoor situation while that for the outdoor situation is shown in Fig.4 (b), respectively.

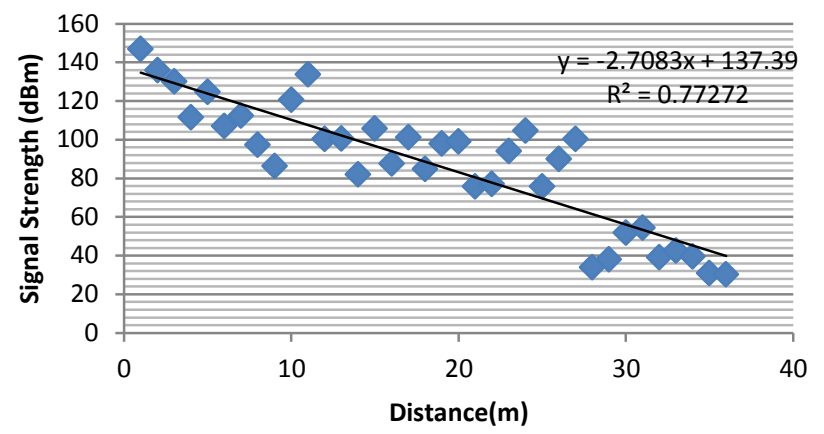

(a)Indoor

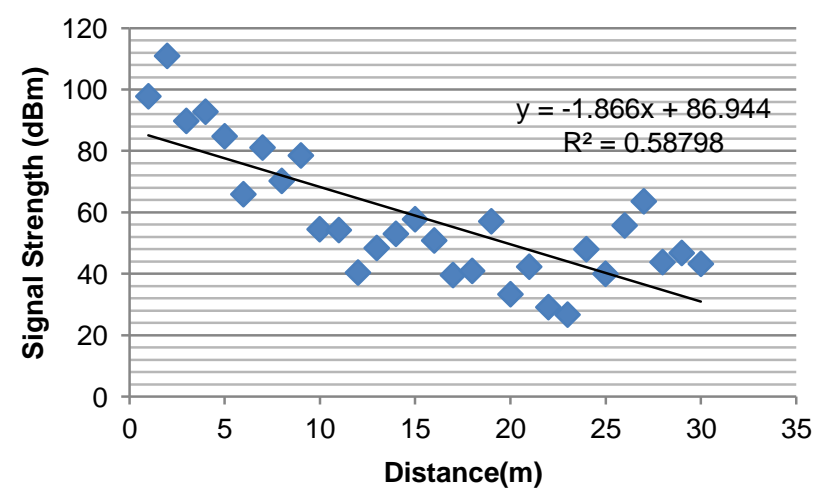

(b)Outdoor

Fig. 4. Measured signal strength of ZigBee receiver as a function of distance between transmitter and receiver

Signal strength in the case of outdoor situation is rather weak in comparison to that for indoor situation. Therefore, correlation between signal strength and distance is not so high for outdoor situation which results in relatively poor location estimation accuracy for ZigBee based location estimation method.

There is no error when the position is situated at the cross point among three circles of which the locations of $\mathrm{WiFi}$ routers and ZigBee transmitters are situated as shown in Fig.5 (a). On the other hand, some errors would occur in the situations which is shown in Fig.5 (b) for both WiFi router based and ZigBee based location estimation methods, Location estimate has to be made at the location as gravity center of the triangle which is formed with three circles 


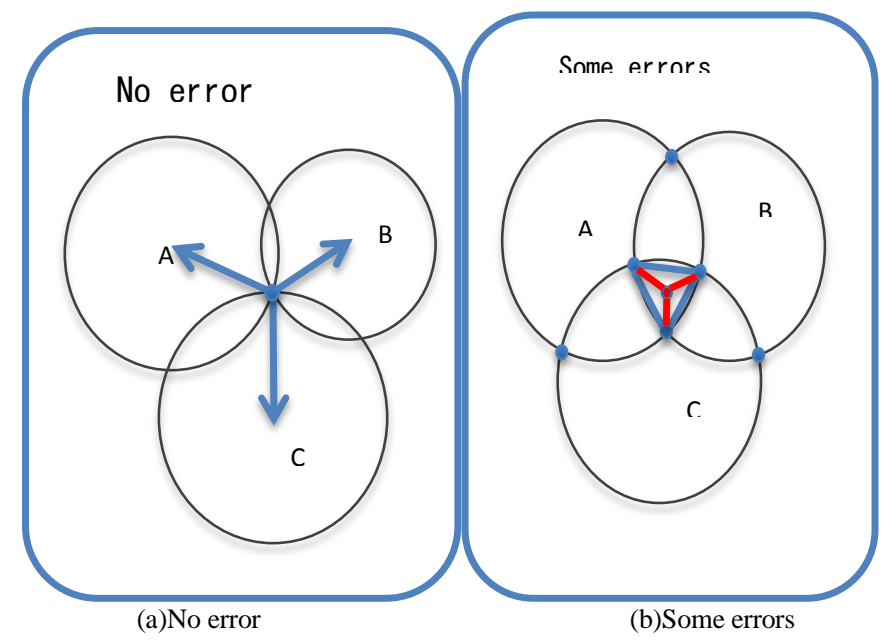

Fig. 5. Situation when some errors occurrence

\section{B. Location Estimation Accuracy Assessment}

Location estimation accuracy of three location estimation methods with GPS, WiFi beacon and ZigBee is assessed for both indoor and outdoor situations. The actual location is the $7^{\text {th }}$ building of the Science and Engineering Faculty of Saga University for indoor situation (Collider on the fourth floor). Meanwhile, outdoor is situated at the southern portion of the $7^{\text {th }}$ building (Parking lot). Fig.6 (a) shows exact measured locations with GPS, WiFi beacon and ZigBee based methods while Fig.6 (b) shows probability density function of the measured location errors for WiFi beacon and ZigBee based methods.

The measured locations with GPS based method have obvious and significant bias error due to the fact that radio wave from GPS satellites comes from the left windows nearby the receiver. Even for the measured locations with $\mathrm{WiFi}$ beacon and ZigBee based methods have 4 to 5 meters of bias errors. In terms of mean and standard deviation, ZigBee based method is superior to WiFi beacon based method.

Meanwhile, Fig.7 (a) shows the measured locations in outdoor situation for GPS, WiFi beacon and ZigBee based methods. On the other hand, Fig.7 (b) shows probability density function of the measured location errors.

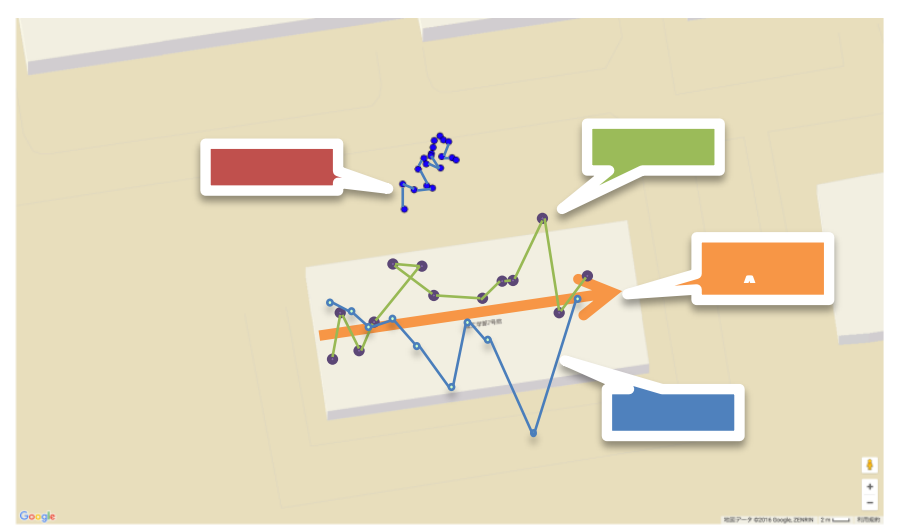

(a)Measured locations

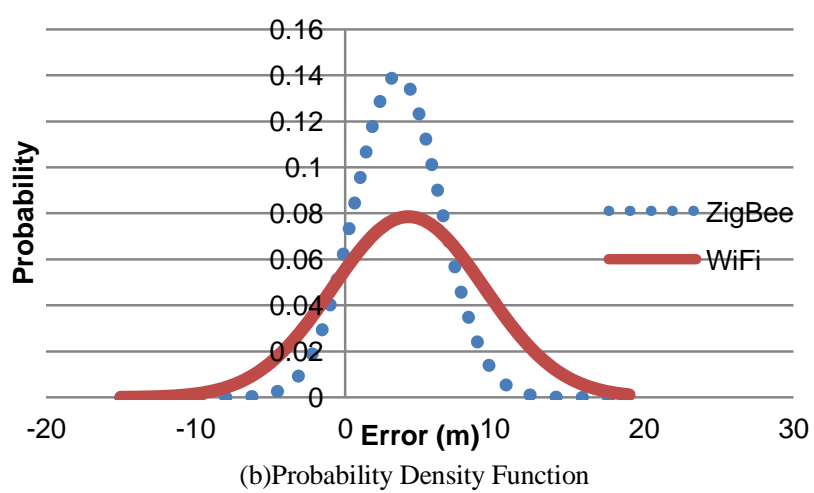

Fig. 6. Location estimation accuracy in indoor and outdoor situations

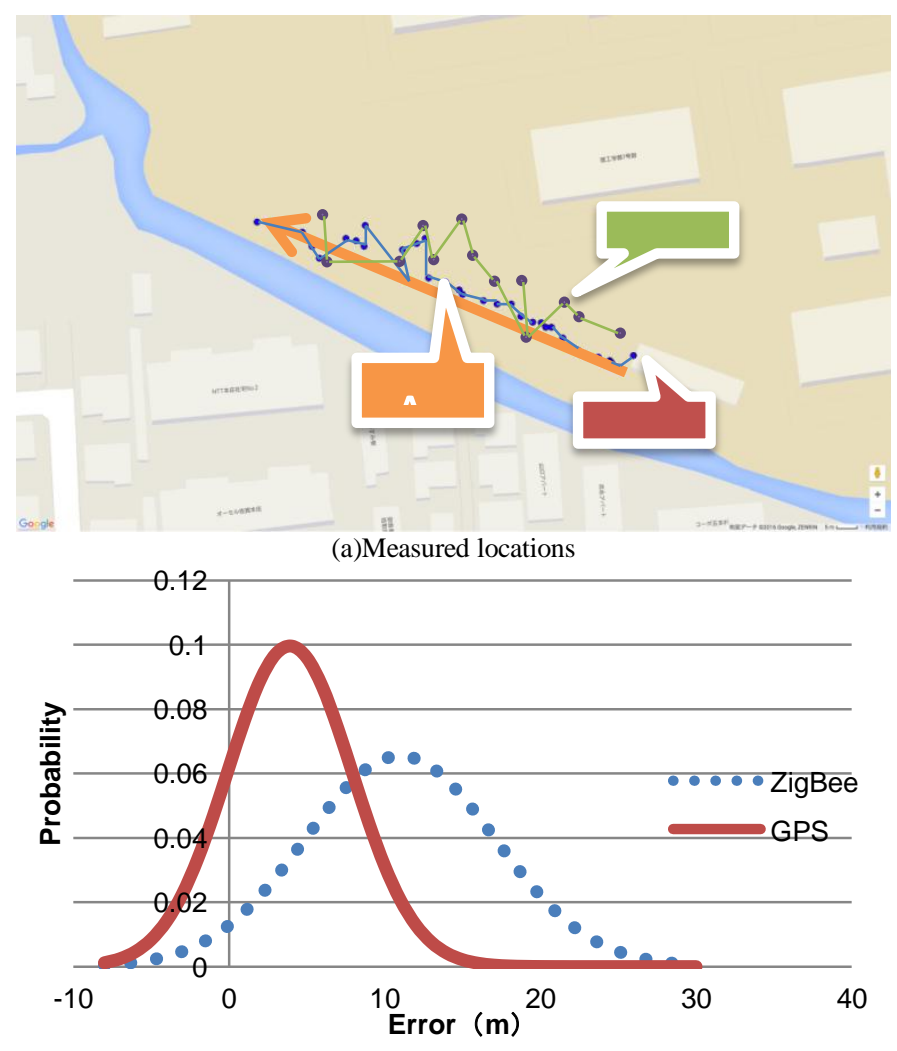

(b)Probability Density Function

Fig. 7. Location estimation accuracy in indoor and outdoor situations

In the case of ZigBee based location estimation, the locations and layouts of transmitters are key for location estimation accuracy. For both cases of location estimations with ZigBee based method between indoor and outdoor situations, just three transmitters are used for location estimations. In the case of outdoor situation, GPS based method is superior to ZigBee based method. GPS based method shows $3 \mathrm{~m}$ of bias error while ZigBee based method shows $11 \mathrm{~m}$ of bias error.

Mean and standard deviation of location estimation error for both ZigBee and WiFi based location estimation methods in indoor and outdoor situations are shown in Table 1 and 2, respectively. 
TABLE I. MEAN AND STANDARD DEVIATION OF LOCATION ESTIMATION ERROR IN THE CASE OF INDOOR SITUATION

\begin{tabular}{|l|l|c|}
\hline & ZigBee & WiFi \\
\hline Mean: $\mu$ & 3.51 & 4.24 \\
\hline Standard Deviation: $\sigma$ & 2.85 & 5.08 \\
\hline
\end{tabular}

TABLE II. MEAN AND STANDARd DEVIATION OF LOCATION ESTIMATION ERROR IN THE CASE OF OUTDOOR SITUATION

\begin{tabular}{|l|l|l|}
\hline & ZigBee & GPS \\
\hline Mean: $\mu$ & 11 & 3.90 \\
\hline Standard Deviation: $\sigma$ & 6.09 & 4.00 \\
\hline
\end{tabular}

\section{Relation Between Location Estimation Error and Rescue} Time

By using GAMA simulation platform, relation between location estimation error and rescue time is clarified. Fig.8 shows road network and the initial positions of victim who needs a help for evacuation (with wheel chair), shelter (green colored house), rescue people (blue colored person), and the measured location (Orange colored circle).

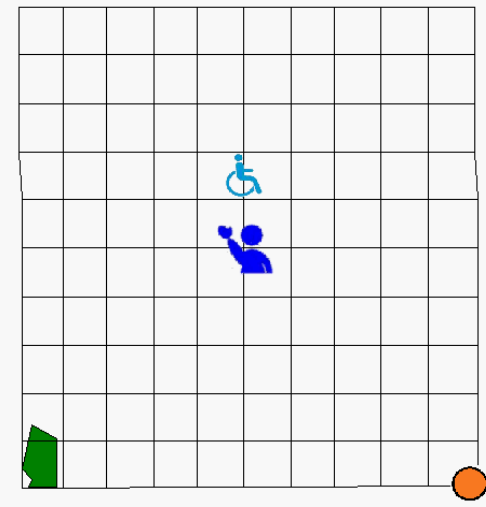

Fig. 8. Initial locations of victim, shelter, recue people and the measured location

The simulation result is shown in Fig.9.

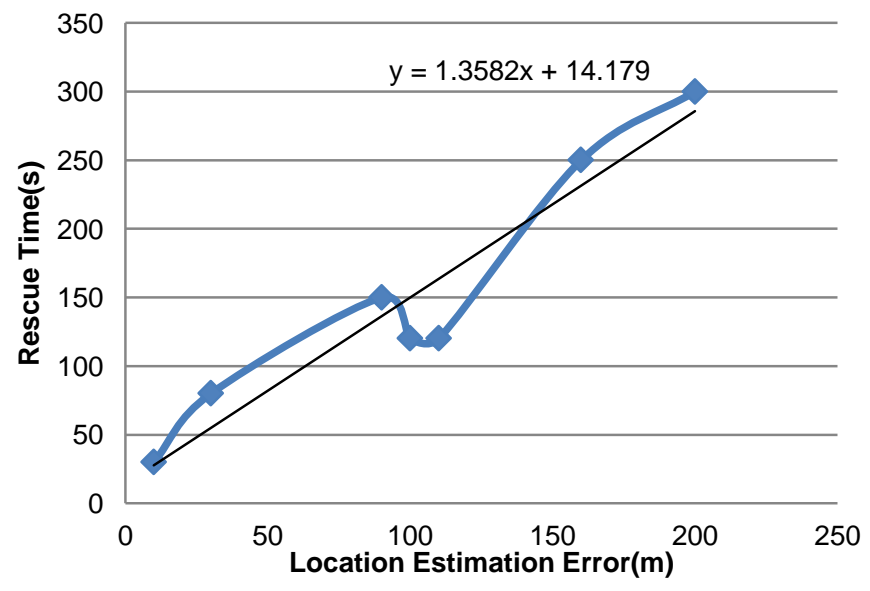

Fig. 9. Relation between location estimation error and rescue time
Even if there is no location estimation error, 14.179 of rescue time is required. In accordance with the location estimation error, rescue time is increased. Linear regressive analysis shows the following relation,

$$
y=1.3582 x+14.179
$$

where $x$ and $y$ denotes location estimation error and rescue time, respectively.

\section{RESCUE SIMULATION}

\section{A. Rescue Simulation Model}

The centralized rescue model is presented which has three types of agent: volunteers, disabled people and route network. The route network is also considered as an agent because the condition of traffic in certain route can be changed when disaster occurs. The general rescue model is shown in Fig.10.

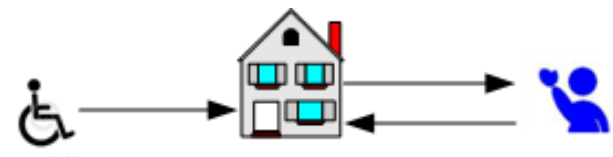

Fig. 10. Centralized Rescue Model

As shown in Fig.10, the concepts of the proposed rescue system. There are three major components, persons who need a help for evacuation, Information Collection Center: ICC for health, traffic, and the other conditions together with the location and attitude information of the persons who need a help and the rescue peoples. Body attached sensors allow measurements of health conditions and the location and attitude of the persons who need a help. The measured data can be transmitted to the ICC through smart-phone, or i-phone, or tablet terminals of which the persons who need a help are carrying. By using the collected health condition and the location/attitude as well as traffic condition information, most appropriate rescue peoples are determined by the person by the person.

\section{B. Road Network and Initial Positions of Victims, Rescue Peoples, Shelters}

The sample GIS map consists of 5 layers: road, building, rescue peoples (volunteer agents), victims (disabled persons) and shelter. Fig.11 shows the map.

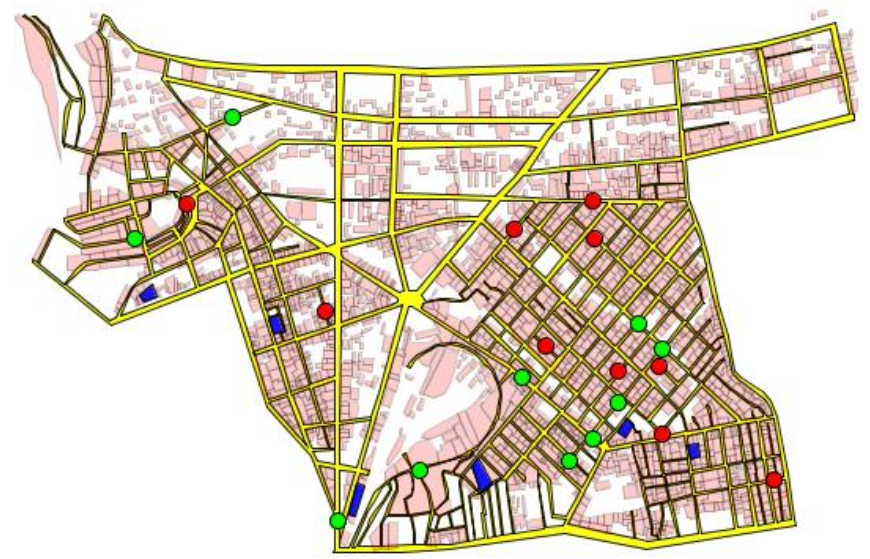

Fig. 11. Road network and the initial locations of victims, rescue peoples, shelters 
The red points and green points indicate the locations of disabled persons and locations of volunteers respectively. These locations are generated randomly along the roads. Blue buildings are shelters. The initial health level of disabled persons is generated randomly between 100 and 500. Every time step of simulation, these health levels decrease by 0.5 . If the health level is equal to zero, the corresponding agent is considered as dead. The movements of volunteer agents are controlled by Morimoto Traffic Simulator.

\section{Task Allocation Model}

The decision making of volunteers to help disabled persons can be treated as a task allocation problem [10]-[14]. The task allocation for rescue scenario is carried out by the central agents. The task of volunteers is to help disabled persons; this task has to be allocated as to which volunteers should help which disabled persons in order to maximize the number of survivals.

We utilize the combinatorial auction mechanism to solve this task allocation problem. At this model, the volunteers are the bidders; the disabled persons are the items; and the emergency center is the auctioneer. The distance and health level of disabled person are used as the cost for the bid. When the rescue process starts, emergency center creates a list of victims, sets the initial distance for victims, and broadcasts the information to all the volunteer agents. Only the volunteer agents whose distance to victims is less than the initial distance will help these victims. It means that each volunteer agent just help the victims within the initial distance instead of helping all the victims. The initial distance will help volunteers to reduce the number of task so that the decision making will be faster.

\section{Rescue Simulation Results for the Case Without Any Error}

With a fixed number of disabled persons and the number of volunteers increase, the correlation between number of volunteers and rescue time is shown in Fig. 12.

\section{Rescue Time(s)}

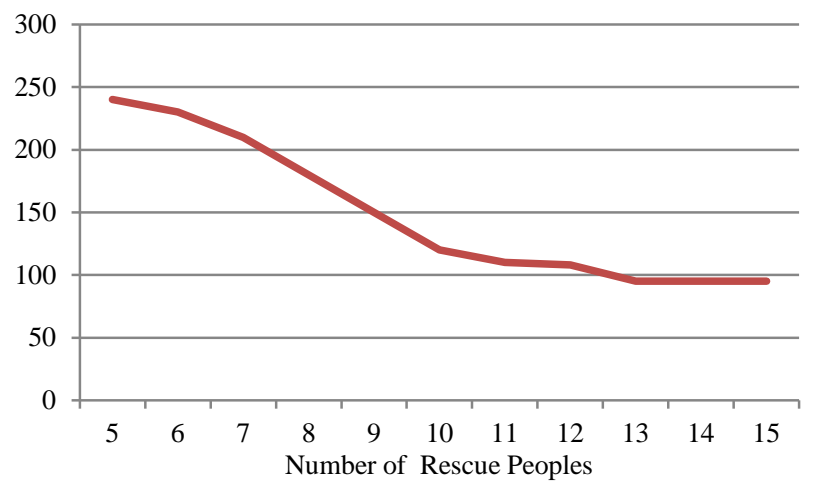

Fig. 12. Correlation between Number of Volunteers and Rescue Time

With a fixed number of volunteers and the number of disabled persons increase, the correlation between number of disabled persons and rescue time is shown in Fig.13.

\section{Rescue Time(s)}

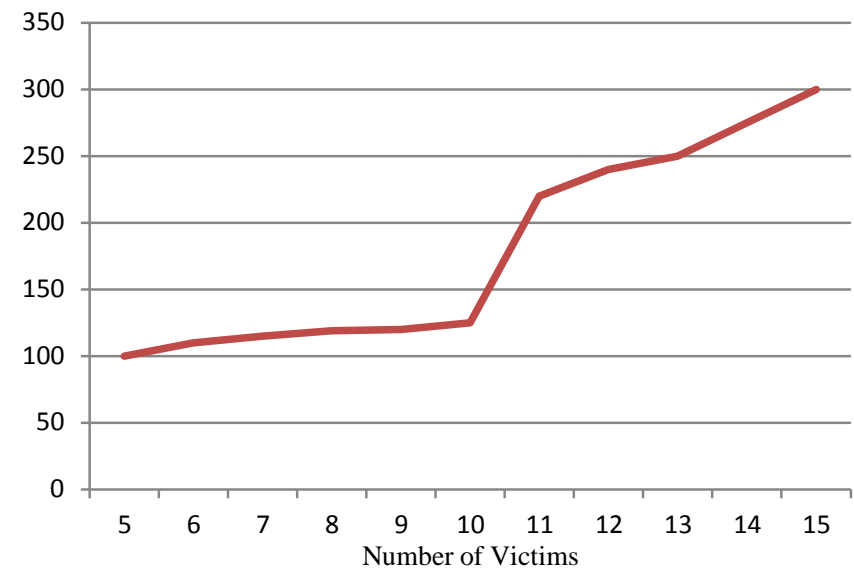

Fig. 13. Correlation between Number of Disabled Persons and Rescue Time

The number of volunteers and the number of disabled persons are fixed, whereas the number of vehicle increases. We test with the total length of road of 500 meters. The increasing number of vehicles will make traffic density higher. The correlation between number of vehicle and rescue time is shown in Fig.14.

\section{Rescue Time(s)}

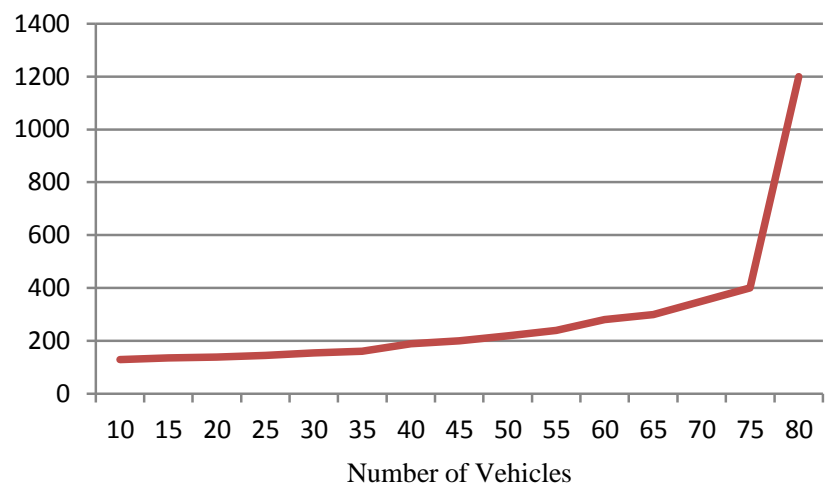

Fig. 14. Correlation between Number of Vehicles and Rescue Time

\section{E. Rescue Simulation Results of the Proposed Location Estimation Method}

The results of Fig.12 to 14 are for the case of no location estimation error. Meanwhile, the simulation results taking into account location estimation errors are shown in Fig.15. The basic idea of the proposed location estimation method is that three different location estimation methods are switched depending on the circumstances of the locations of radio wave absorbance, the number of access points (WiFi routers), the number of acquired GPS satellites, and the number of ZigBee transmitters. As shown in Fig.7, rescue time is increased when location estimation error is taken into account even if the best accuracy of location estimation method is selected. The rescue 
time for the case of which location estimation error is taken into account is evaluated. Around 10 to 20 seconds are required additionally in comparison to the rescue time without consideration of location estimation error.

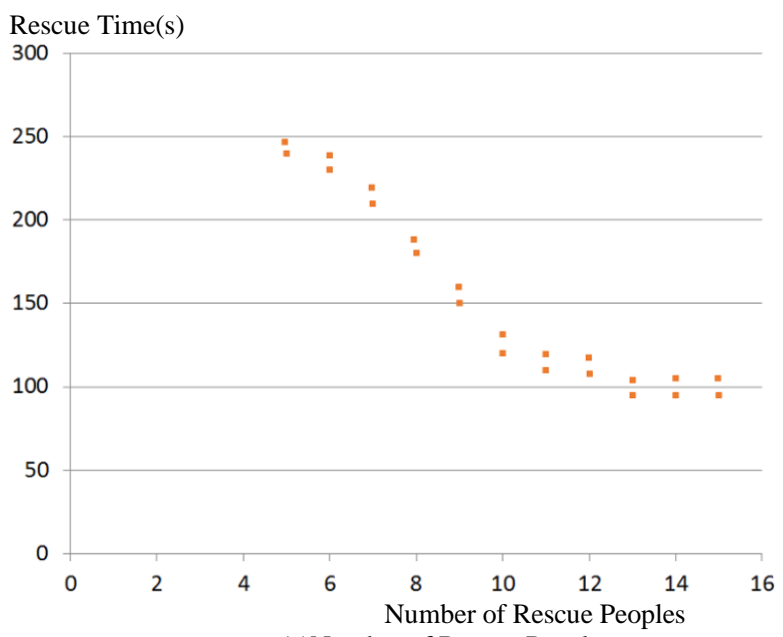

(a)Number of Rescue Peoples

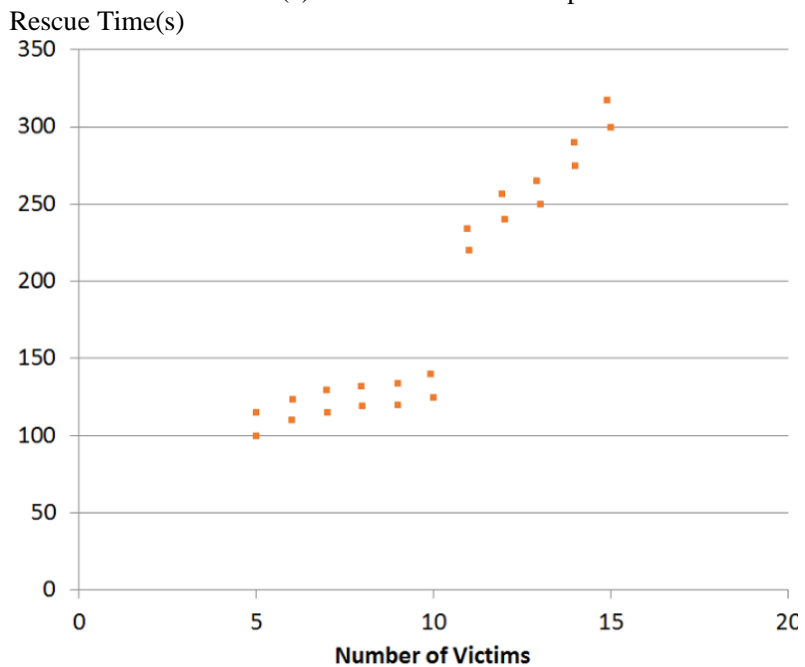

Number of Victims

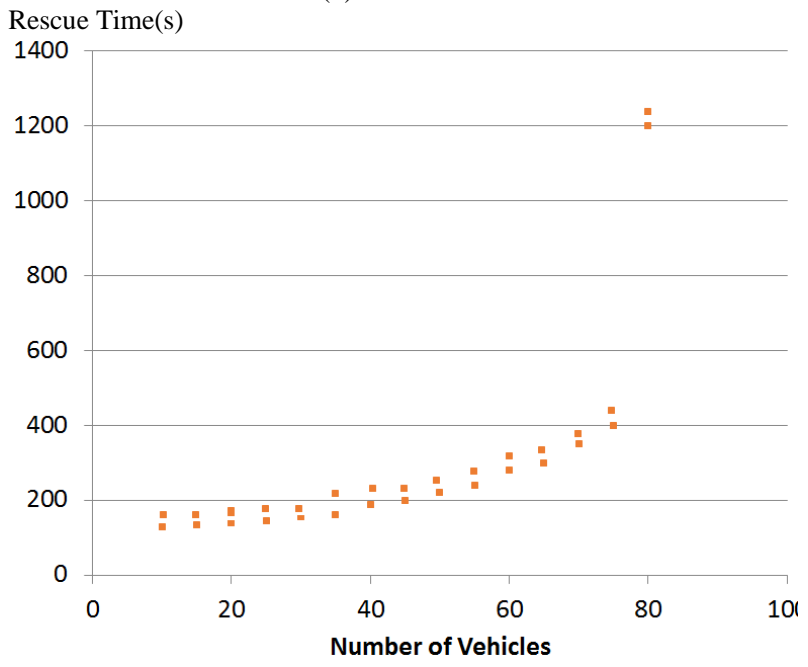

(c)Number of Vehicles

Fig. 15. Rescue time for the case of which location estimation error is taken into account

\section{CONCLUSION}

Location monitoring system for rescue disable persons by switching the location estimation methods with GPS, ZigBee and WiFi beacon is proposed. Rescue system with triage using health condition monitoring together with location and attitude monitoring as well as the other data acquired with mobile devices is evaluated with the proposed location monitoring system. Through simulation study, influence due to location estimation error on rescue time is evaluated together with effect of the proposed location monitoring system. Also, it is found that the effect of triage on rescue time is clarified.

Further study is required for clarifying effects of triage on reducing rescue time in actual situations.

\section{ACKNOWLEDGMENT}

The author would like to thank Dr. Trang Xuang Sang of Vinh University in Vietnam for his effort to conduct simulation studies.

\section{REFERENCES}

[1] C. Ren, C. Yang, and S. Jin, "Agent-Based Modeling and Simulation on emergency", Complex 2009, Part II, LNICST 5, 1451 - 1461, 2009.

[2] M. H. Zaharia , F. Leon, C. Pal, and G. Pagu, "Agent-Based Simulation of Crowd Evacuation Behavior", International Conference on Automatic Control, Modeling and Simulation, 529-533, 2011.

[3] C. T. Quang, and A. Drogoul, "Agent-based simulation: definition, applications and perspectives", Invited Talk for the biannual Conference of the Faculty of Computer Science, Mathematics and Mechanics, 2008.

[4] Z. Bo, and V. Satish, "Agent-based modeling for household level hurricane evacuation”, Winter Simulation Conference, 2009.

[5] J. W. Cole, C. E. Sabel, E. Blumenthal,K. Finnis, A. Dantas,S. Barnard, and D. M. Johnston, "GIS-based emergency and evacuation planning for volcanic hazards in New Zealand", Bulletin of the New Zealand society for earthquake engineering, vol. 38, no. 3, 2005.

[6] M. Batty, "Agent-Based Technologies and GIS: simulating crowding, panic, and disaster management", Frontiers of geographic information technology, chapter 4, 81-101, 2005

[7] T. Patrick, and A. Drogoul, "From GIS Data to GIS Agents Modeling with the GAMA simulation platform", TF SIM 2010.

[8] J. Kaprzy Edt., Kohei Arai, Rescue System for Elderly and Disabled Persons Using Wearable Physical and Psychological Monitoring System, Studies in Computer Intelligence, 542, 45-64, Springer Publishing Co. Ltd., 2014.

[9] K.Arai, T.X.Sang, Emergency rescue simulation for disabled persons with help from volunteers, International Journal of Research and Review on Computer Science, 3, 2, 1543-1547, 2012.

[10] K.Arai, Wearable healthy monitoring sensor network and its application to evacuation and rescue information server system for disabled and elderly person, International Journal of Research and Review on Computer Science, 3, 3, 1633-1639, 2012.

[11] K.Arai, T.X.Sang, N.T.Uyen, Task allocation model for rescue disable persons in disaster area with help of volunteers, International Journal of Advanced Computer Science and Applications, 3, 7, 96-101, 2012.

[12] Kohei Arai, Tran Xuan Sang, Decision making and emergency communication system in rescue simulation for people with disabilities, International Journal of Advanced Research in Artificial Intelligence, 2, 3, 77-85, 2013.

[13] Kohei Arai, Frequent physical health monitoring as vital sign with psychological status monitoring for search and rescue of handicapped, disabled and elderly persons, International Journal of Advanced Research in Artificial Intelligence, 2, 11, 25-31, 2013.

[14] Kohei Arai, Vital sign and location/attitude monitoring with sensor networks for the proposed rescue system for disabled and elderly persons who need a help in evacuation from disaster areas, International 
Journal of Advanced Research in Artificial Intelligence, 3, 1, 24-33, 2014.

[15] Kohei Arai, Method and system for human action detection with acceleration sensors for the proposed rescue system for disabled and elderly persons who need a help in evacuation from disaster areas, International Journal of Advanced Research in Artificial Intelligence, 3, 1, 34-40, 2014.

[16] Kohei Arai, Method and system for human action detection with acceleration sensors for the proposed rescue system for disabled and elderly persons who need a help in evacuation from disaster areas, International Journal of Advanced Research in Artificial Intelligence, 3, 1, 34-40, 2014.

[17] Kohei Arai, Taka Eguchi, Realistic rescue simulation method with consideration of roadnetwork ristrictions, International Journal of Advanced Research on Artificial Intelligence, 4, 7, 21-28, 2015.

[18] K.Arai, T.X. Sang, Multi agent based rescue simulation for disabled persons with the help of volunteers in emergency situation, Proceedings of the 260th conference in Saga of Image and Electronics Engineering Society of Japan, 81-85, 2012.

[19] Kohei Arai, Rescue system with sensor network for physical and psychological health monitoring, Proceedings of the International Seminar on Intelligent Technology and Its Applications: ISITIA 2015, (Keynote Speech), 2015.
[20] Kohei Arai, Rescue system with sensor network for physical and psychological health monitoring, Proceedings of the SAI Confeernce 2015

\section{AUTHORS PROFILE}

Kohei Aarai He received BS, MS and PhD degrees in 1972, 1974 and 1982, respectively. He was with The Institute for Industrial Science and Technology of the University of Tokyo from April 1974 to December 1978 and also was with National Space Development Agency of Japan from January, 1979 to March, 1990. During from 1985 to 1987, he was with Canada Centre for Remote Sensing as a Post Doctoral Fellow of National Science and Engineering Research Council of Canada. He moved to Saga University as a Professor in Department of Information Science on April 1990. He was a councilor for the Aeronautics and Space related to the Technology Committee of the Ministry of Science and Technology during from 1998 to 2000. He was a councilor of Saga University for 2002 and 2003. He also was an executive councilor for the Remote Sensing Society of Japan for 2003 to 2005 . He is an Adjunct Professor of University of Arizona, USA since 1998. He also is Vice Chairman of the Commission-A of ICSU/COSPAR since 2008. He wrote 33 books and published 510 journal papers. He is Editor-in-Chief of International Journal of Advanced Computer Science: IJACSA and Applications as well as International Journal of Intelligent Systsems and Applications: IJISA. http://teagis.ip.is.saga-u.ac.jp/index.html 